\title{
BIOLOGIA FLORAL E VIABILIDADE DE PÓLEN EM CULTIVARES DE CAQUIZEIRO (Diospyros kaki L.) E Diospyros virginiana L. ${ }^{1}$
}

\author{
SAMANTA SIQUEIRA DE CAMPOS ${ }^{2}$, MARIA TERESA SCHIFINO WITTMANN ${ }^{3}$, \\ SERGIO FRANCISCO SCHWARZ ${ }^{4}$, PEDRO AUGUSTO VEIT 5
}

RESUMO - O caquizeiro é uma planta muito complexa na questão de sua biologia floral, já que pode apresentar três tipos de flor (feminina, masculina ou hermafrodita) ou apenas flores femininas, como no caso das cultivares comerciais. O objetivo deste trabalho foi estudar o período de florescimento, os tipos de flores e estimar a viabilidade dos grãos de pólen em nove cultivares de D. kaki e em D. virginiana. As cultivares Pomelo e Rama Forte foram precoces para o início do florescimento. A cultivar Pomelo e a espécie D. virginiana apresentaram produção de flores masculinas, com pólen viável. As nove cultivares de $D$. kaki estudadas apresentaram produção de flores femininas (também masculinas em Pomelo) como esperado em cultivares comerciais. Porém a cultivar Mikado apresentou, ao final do florescimento, flores com produção de pólen viável, o que ainda não havia sido relatado. A viabilidade dos grãos de pólen, em geral, foi acima de $90 \%$ para as cultivares Pomelo e Mikado, e para D. virginiana.

Termos para indexação: caqui, fenologia, viabilidade do pólen, florescimento.

\section{FLORAL BIOLOGY AND POLLEN VIABILITY IN JAPANESE PERSIMMON CULTIVARS (Diospyros kaki L.) AND Diospyros virginiana L.}

\begin{abstract}
Persimmon tree is a very complex plant regarding floral biology, because it can present three types of flower (female, male or hermaphrodite) or only female as in the commercial cultivars. The objective of this research was to study the flowering period, flower types and to estimate pollen grains viability in nine D. kaki cultivars and in D. virginiana. Cultivars Pomelo and Rama Forte were the earliest for flowering beginning. Cultivar Pomelo and $D$. virginiana produced male flowers with viable pollen. The nine studied D. kaki cultivars presented females flowers (also male in Pomelo) as expected in commercial cultivars. Unexpectedly, cultivar Mikado presented male flowers with viable pollen at the end of the flowering period, what had not been previously reported. Pollen viability was generally over $90 \%$ for Pomelo, Mikado and D. virginiana.
\end{abstract}

Index terms: persimmon, phenology, pollen viability, flowering.

\footnotetext{
${ }^{1}$ (Trabalho 154-14). Recebido em: 09-05-2014. Aceito para publicação em: 20-11-2014.

${ }^{2}$ Msc, Eng ${ }^{\mathrm{a}}$.Agr ${ }^{\mathrm{a}}$., doutoranda PPG Fitotecnia - PPG Fitotecnia - UFRGS, bolsista CAPES. Departamento de Horticultura e Silvicultura, Faculdade de Agronomia, Universidade Federal do Rio Grande do Sul. Av. Bento Gonçalves, 7712. Caixa Postal 15100, CEP 91540000, Porto Alegre-RS. E-mail: ssiqueiradecampos@yahoo.com.br

${ }^{3}$ Dra. Professora do Departamento de Plantas Forrageiras e Agrometeorologia e do Programa de Pós-graduação em Fitotecnia, Faculdade de Agronomia, Universidade Federal do Rio Grande do Sul. Av. Bento Gonçalves, 7712, Caixa Postal 15100, CEP 91501970, Porto Alegre-RS. E-mail: mtschif@ufrgs.br

${ }^{4}$ Dr. Prof. do Departamento de Horticultura e Silvicultura e do Programa de Pós-graduação em Fitotecnia, Faculdade de Agronomia, UFRGS. Bolsista CNPq. Av. Bento Gonçalves, 7712, Caixa Postal 15100, CEP 91540-000, Porto Alegre, RS. E-mail: schwarz@ufrgs.br ${ }_{5}^{5}$ Eng. Agr, mestrando PPG Fitotecnia - UFRGS, bolsista CAPES. Departamento de Horticultura e Silvicultura, Faculdade de Agronomia, Universidade Federal do Rio Grande do Sul. Av. Bento Gonçalves, 7712. Caixa Postal 15100, CEP 91540-000, Porto Alegre-RS. E-mail: pedro.veit@ufrgs.br
} 


\section{INTRODUÇÃO}

O caquizeiro (Diospyros kaki L.) é originário da região Asiática, China e Japão. Tem como centro de origem e principal centro de diversidade as montanhas da região central da China. O Japão é considerado um centro secundário para a espécie. $\mathrm{O}$ caquizeiro americano (D. virginiana L.) é originário dos Estados Unidos, no Brasil este é utilizado como porta-enxerto e seus frutos não são consumidos.

A cultura do caquizeiro (D. kaki) espalhou-se do continente asiático para outras regiões de clima temperado e subtropical, sendo cultivado em vários países. No Brasil, após 1920, houve expansão da área cultivada (MARTINS;PEREIRA, 1989), sendo hoje considerado o quarto produtor mundial, com aproximadamente 155 mil toneladas de caqui.

No mundo, mais de um milhão de toneladas de caqui são produzidos anualmente, ocupando área de aproximadamente 235.000 ha. Segundo a FAO (2014), em 2012, os principais produtores do mundo, em ordem decrescente, foram: China, República da Coreia, Japão, Brasil e Azerbaijão. No Brasil, as regiões que se destacaram em 2012 foram Sudeste e Sul, onde os Estados de São Paulo e Rio Grande do Sul produziram 79 mil toneladas e 34 mil toneladas, respectivamente (IBGE, 2014).

No Rio Grande do Sul, têm-se algumas peculiaridades para a cultura que demonstram destaque, com boa adaptação ao clima do Estado, colheita de frutos de qualidade e baixo uso de defensivos agrícolas no pomar. Isso tem permitido o desenvolvimento da cultura com aumento da área plantada e maior aceitação da fruta pelo mercado local. Além disto, é uma cultura complementar para pequenos agricultores devido ao fato de que a colheita ocorre em período escasso de oferta de frutas no mercado.

Destacam-se como maiores produtores de caqui os municípios de Caxias do Sul, Farroupilha e Bento Gonçalves, todos na Serra Gaúcha. As principais cultivares produzidas nesses municípios são ‘Fuyu’ e ‘Kyoto’ (GRELLMANN, 2003).

O hábito floral do caquizeiro é muito complexo, e, dependendo da cultivar, a planta pode apresentar três tipos de flores (femininas, masculinas e hermafroditas) na mesma planta ou apenas um tipo deste. Na maioria das cultivares comerciais, ocorrem apenas flores femininas, como também a tendência para produção de frutos partenocárpicos, ou seja, sem sementes, pois frutificaram sem ter ocorrido polinização (MARTINS;PEREIRA, 1989).

Yasui (1915) descreveu que dados anteriores ao seu trabalho já sugeriam que $D$. kaki seria naturalmente uma planta monoica e que estaria em vias de perder esse caráter de produzir flores estaminadas devido à forma de cultivo. No Japão, as árvores estaminadas foram continuamente destruídas inconscientemente, pois as melhores cultivares eram propagadas sempre por enxertia. Portanto, muitas plantas estaminadas foram eliminadas, e as plantas pistiladas tomaram seu lugar.

A polinização na espécie $D$. kaki é entomófila, quando há a presença de plantas polinizadoras no pomar e é realizada principalmente por abelhas da espécie Apis melifera (MARTINS; PEREIRA, 1989; AGUSTÍ, 2010).

Segundo Agustí (2010), devido à partenocarpia, em pomares comerciais de caquizeiro, encontram-se apenas cultivares com produção de flores femininas, o que contribui para baixa taxa de frutificação. Uma alternativa seria manter algumas plantas produtoras de flores masculinas, com produção de pólen viável, no pomar, a fim de aumentar a frutificação efetiva e, consequentemente, aumentar a produtividade.

O estudo da fenologia é importante porque relaciona o clima com o ciclo da planta em suas diferentes fases (brotação, florescimento, frutificação, etc.) durante seu desenvolvimento. Através do monitoramento do crescimento vegetativo e reprodutivo das plantas, obtêm-se dados de suas respostas às mudanças sazonais e climáticas do ambiente. Assim, é possível utilizar esses dados em tratamentos fitossanitários, adubações de cobertura, práticas de poda ou na observação de um evento importante como geadas ou estresse hídrico, associados a estádios bem definidos no desenvolvimento das plantas (MORELLATO, 2007).

O objetivo deste trabalho foi estudar o período de florescimento, os tipos de flores e estimar a viabilidade dos grãos de pólen em nove cultivares de $D$. kaki e $D$. virginiana. A fim de disponibilizar informações aos produtores e programas de melhoramento, além de incrementar a produção de caqui e a qualidade dos frutos.

\section{MATERIAL E MÉTODOS}

As plantas em estudo pertencem à coleção de caquizeiro localizada na Estação Experimental Agronômica (3006'S e 51 $39^{\circ}$ 'W e altitude de $35 \mathrm{~m}$ ), da Universidade Federal do Rio Grande do Sul, em Eldorado do Sul-RS. O solo da área experimental é classificado como Argissolo Vermelho distrófico típico (STRECK et al., 2008), com declividade média de $12,5 \%$. Segundo a classificação de Köeppen, a região apresenta clima subtropical úmido, de verão 
quente, do tipo Cfa. A precipitação pluviométrica média anual é de $1.440 \mathrm{~mm}$, temperatura média anual de $18,8^{\circ} \mathrm{C}$ e a umidade relativa média do ar de 77,3 $\%$ (BERGAMASCHI et al., 2003). O pomar, com aproximadamente 1 ha, foi estabelecido na década de 80 . Foram avaliadas, nos ciclos produtivos de 2011/2012 e 2012/2013, nove cultivares de D. kaki (Costata, Fuyu, Kaoru, Mikado, Okira, Pomelo, Rama Forte, Regina, Taubaté) enxertadas sobre $D$. virginiana e a espécie $D$. virginiana de pé-franco.

Nos ciclos produtivos em estudo, os tratos culturais realizados no pomar foram a poda de frutificação (03-08-2012 e 04-08-2013), roçada nas entrelinhas (no período de primavera a outono) para o controle de plantas daninhas, adubação, segundo a recomendação para a cultura (COMISSÃO DE QUÍMICA E FERTILIDADE DO SOLO - RS/SC, 2004) e formicida para controlar o ataque de formigas cortadeiras. Nenhum tratamento para quebra de dormência foi realizado. Em $D$. virginiana não foram realizadas podas.

Avaliações semanais foram feitas para determinar o estádio de florescimento (desde o surgimento dos botões florais até a queda das flores). Inicialmente, foi observado o surgimento dos primeiros botões florais, até o seu completo desenvolvimento em forma de balão, com as pétalas de cor creme, seguida do estádio de antese, após mudança na cor das pétalas, de brancas a uma coloração mais escura, e por fim sua queda, segundo García-Carbonell et al.(2002). As plantas foram consideradas em pleno florescimento quando havia 50\% das flores em antese. Foram coletadas flores para análise dos grãos de pólen (segundo metodologia de CAVALCANTE et al., 2000) e também para classificar o tipo de flor produzida. Os botões florais foram coletados ainda fechados, em estádio de balão (estádio de maturação avançado com a presença de pólen maduro). Os botões eram imediatamente fixados em solução de etanol:ácido acético $(3: 1)$ e transportados para o Laboratório de Citogenética, do Departamento de Plantas Forrageiras e Agrometeorologia da UFRGS. Após 24h, foram transferidos para álcool $70 \%$ e conservados em freezer até a análise. Foram avaliadas dez flores por planta e 1.000 grãos por flor. Para o preparo das lâminas, as anteras foram cortadas ao meio e, com auxílio de agulha histológica, espalharam-se os grãos de pólen na lâmina com corante carmim propiônico. Consideraram-se viáveis aqueles grãos bem corados e túrgidos, e inviáveis os não corados e/ou murchos. Foram feitas medições do eixo transversal e longitudinal em 20 grãos de pólen classificados como normais, 10 grãos pequenos e 10 grãos maiores que os normais. E foi observada a possível ocorrência de grãos de pólen com cerca de $30-40 \%$ a mais do tamanho normal, o que é um indicativo de gametas não reduzidos. Gametas não reduzidos são aqueles que apresentam número cromossômico somático devido a anormalidades ocorridas durante a meiose (RAMSEY; SCHEMSKE, 1998).

Os resultados obtidos, para a viabilidade do grão de pólen, foram analisados estatisticamente, pelo teste de Tukey, a 5\% de probabilidade.

\section{RESULTADOS E DISCUSSÃO}

O estádio de florescimento ocorreu em diferentes períodos, com diferença de mais ou menos sete dias (Tabela 1). Durante o período de floração do caquizeiro, nos dois ciclos de produção, foi observada a presença de abelhas (Apis melifera).

As cultivares Rama Forte e Pomelo foram precoces, nos dois ciclos de produção avaliados, sendo que o início do florescimento ocorreu em 22-08-2012 e 30-08-2013, respectivamente, sendo isto um indicativo de que estas cultivares são mais indicadas para regiões mais quentes, permitindo assim uma acentuação desta precocidade. O florescimento das demais cultivares iniciou-se a partir de 07-09-2012 e 13-09-2013. No ciclo produtivo de 2011/2012, as cultivares Regina, Kaoru, Costata, Okira, Rama Forte e Pomelo atingiram o pleno florescimento em 21-09-2012, mas no ciclo de 2012/2013, o florescimento pleno variou de 20-092013 a 10-10-2013.

No ciclo produtivo de $2011 / 2012$, o final do florescimento, marcado pela queda das pétalas e surgimento de frutos, foi registrado em 27-09-2012 para 'Rama Forte', 05-10-2012 com 'Pomelo', 'Regina', 'Kaoru', 11-10-2012 para 'Taubaté', 'Costata', 'Okira' e 'Mikado' e 19-10-2012 em 'Fuyu'. No ciclo de 2012/2013, o final do período de florescimento ocorreu durante o mês de outubro para a maioria das cultivares, exceto para 'Regina', que se verificou na última semana de setembro (Tabela 1).

Grellmann et al. (2003) estudaram o comportamento fenológico das cultivares Kaoru, Mikado, Fuyu, Rama Forte e Regina durante oito anos, em Veranópolis-RS (região de maior altitude e mais fria que a região do presente trabalho), obtendose resultados para o início e fim do florescimento, no mês de outubro. Porém, em alguns anos, o florescimento iniciou-se em setembro e terminou em novembro, que pode estar relacionado com a idade das plantas e mudanças climáticas ao longo dos anos.

$\mathrm{Na}$ Tabela 1, pode-se observar que, no presente trabalho, comparando-se os dois ciclos 
de avaliação, o início do período de florescimento das cultivares foi mais tardio no segundo ciclo (2012/2013) do que no primeiro (2011/2012).

Nos dois ciclos avaliados, D. virginiana mostrou comportamento diferenciado em relação às cultivares de $D$. kaki quanto ao período de seu florescimento. No ciclo de 2011/2012, o florescimento teve início em 05 de outubro, e no ciclo de 2012/2013, em 10 de outubro, caracterizando-se como período mais tardio em relação às cultivares de $D$. kaki. Este atraso do D. virginiana em relação ao D. kaki indica que o primeiro seria pouco útil em caso de utilizá-lo como polinizador do segundo.

As flores femininas da espécie D. kaki (Figura 1) apresentaram tamanho em torno de $2,5 \mathrm{~cm}$ de diâmetro, cálice de cor verde com quatro lóbulos bem desenvolvidos, pétalas de cor branca a creme, enroladas sobre si. As flores, em geral, apresentaram quatro estames rudimentares (estaminoides) unidos na base da corola. O ovário globoso apresentou quatro cavidades biloculares unidas a quatro estilos, terminando em estigmas. Neste estudo, as características das flores femininas observadas corroboram a descrição feita por Agustí (2010).

Quanto às flores masculinas, tanto em D. kaki como em D. virginiana (Figura 2), apresentaram-se de tamanho menor em relação às flores femininas. As flores estavam dispostas em cachos de três flores com pecíolo curto e apresentaram estames normais, sendo a maioria com 16 estames na base da corola, e as anteras apresentavam grãos de pólen em abundância. As descrições deste estudo são semelhantes às de outros autores, como Martins e Pereira (1989) e Agustí (2010). Alguns autores descrevem a presença de um ovário atrofiado com cerca de 1 a $1,5 \mathrm{~cm}$ de diâmetro. Neste trabalho, não foi observada a presença de ovário rudimentar nas flores masculinas.

Dentre as nove cultivares da espécie $D . k a k i$ estudadas, apenas duas apresentaram flores com produção de pólen, sendo estas 'Pomelo'e 'Mikado', e a espécie $D$. virginiana (Tabelas 2 e 3 ).

Pela análise do tamanho dos grãos de pólen, não foi observada presença de grãos de pólen não reduzidos. Grãos não reduzidos são aqueles com tamanho superior a $40 \%$ do dos normais e podem induzir a poliploidia em plantas (RAMSEY; SCHEMSKE, 1998).

O tamanho dos grãos de pólen ficou na faixa média de $35,49 \mu \mathrm{m}$ a $50,40 \mu \mathrm{m}$ para o eixo transversal e entre $35,44 \mu \mathrm{m}$ e $50,53 \mu \mathrm{m}$ para o eixo longitudinal no ciclo de 2011/2012. Na avaliação do ciclo de 2012/2013, os tamanhos foram entre 36,84 $\mu \mathrm{m}$ e $48,16 \mu \mathrm{m}$ para o eixo transversal e entre 36,98 $\mu \mathrm{m}$ e $51,94 \mu \mathrm{m}$ para o eixo longitudinal (Tabelas 2 e 3). Grygorieva et al. (2010) encontraram valores semelhantes para os grãos de pólen de D. kaki, para o eixo transversal, cuja média foi de $23,56 \mu \mathrm{m}$ a 33,14 $\mu \mathrm{m}$, e o eixo longitudinal estava entre $48 \mu \mathrm{m}$ e 51,39 $\mu \mathrm{m}$, medidos por microscopia eletrônica.

A estimativa da viabilidade do pólen ficou acima dos 90\% para as cultivares Pomelo e Mikado e para $D$. virginiana. Entretanto, ao comparar os dois ciclos, a viabilidade do pólen de 'Mikado' foi maior $(98,39 \%)$ no primeiro em relação ao segundo ciclo $(85,87 \%)$ (Tabelas 2 e 3 e Figura 3$)$.

Já era esperada a presença de pólen na cultivar Pomelo e em $D$. virginiana, pois ambos produzem flores masculinas. A cultivar Pomelo (IAC 6-22) foi desenvolvida, entre outras variedades, pelo programa de melhoramento genético do caquizeiro, Seção de Fruticultura de Clima Temperado, do Instituto Agronômico de Campinas, com intuito de obter variedades pouco exigentes em frio. Além disso, a cultivar destacou-se pela produção regular de flores masculinas, garantindo a autopolinização (OJIMA et al., 1985).

Já para as demais cultivares, esperava-se a presença apenas de flores femininas sem estames funcionais, o que não aconteceu no presente trabalho, pois a cultivar Mikado apresentou flores femininas sem e com estames funcionais.

As demais cultivares (Taubaté, Fuyu, Rama Forte, Regina, Kaoru, Costata, Okira) apresentaram flores femininas com estames não funcionais. Os botões florais da cultivar Mikado, coletados mais próximos ao final do período de florescimento, apresentaram estames com produção de pólen viável, o que implicará a formação de frutos com sementes nesta cultivar. E por ser uma cultivar adstringente, a presença de sementes não irá alterar a cor e o sabor da polpa. A produção de pólen viável também permite o uso desta cultivar em programas de melhoramento.

A ausência de polinização pode implicar frutos sem sementes, denominados de partenocárpicos, os quais são bem aceitos pelo mercado consumidor. Porém, apresentam frutificação efetiva baixa, como no caso da cultivar Fuyu, quando este é partenocárpico. Assim, seria importante realizar estudos com a inclusão de cultivares atuando como polinizadoras, como já ocorre com a ameixeira e macieira, fazendo com que haja aumento na frutificação efetiva e, consequentemente, na produtividade. Como opção, poder-se-ia utilizar a cultivar Pomelo como polinizadora no pomar. 
TABELA 1- Período de florescimento para nove cultivares de $D$. kaki e para a espécie $D$. virginiana cultivadas em Eldorado do Sul-RS, nos ciclos produtivos de 2011/2012 e 2012/2013.

\begin{tabular}{|c|c|c|c|c|c|c|}
\hline \multirow[t]{2}{*}{ Cultivar } & \multicolumn{3}{|c|}{$\begin{array}{c}\text { Florescimento } \\
(2011 / 2012)\end{array}$} & \multicolumn{3}{|c|}{$\begin{array}{c}\text { Florescimento } \\
(2012 / 2013)\end{array}$} \\
\hline & Início & Pleno & Fim & Início & Pleno & Fim \\
\hline Costata & $14 /$ set & $21 /$ set & 11/out & $18 /$ set & 03/out & 10 /out \\
\hline Fuyu & $14 /$ set & 11/out & 19/out & $13 /$ set & $20 /$ set & $17 /$ out \\
\hline Kaoru & $07 /$ set & $21 /$ set & 05/out & $13 / \mathrm{set}$ & $27 /$ set & 03/out \\
\hline Mikado & $07 /$ set & $21 /$ set & $11 /$ out & $13 /$ set & 10/out & $17 /$ out \\
\hline Okira & $07 /$ set & $21 /$ set & $11 /$ out & $20 /$ set & 03/out & $10 /$ out \\
\hline Pomelo & 22/ago & $21 /$ set & $05 /$ out & 30/ago & $27 /$ set & 03/out \\
\hline R. Forte & 22/ago & $21 /$ set & $27 /$ set & 30/ago & $27 /$ set & 03/out \\
\hline Regina & $14 / \mathrm{set}$ & $05 /$ out & $11 /$ out & $13 /$ set & $20 /$ set & $27 /$ set \\
\hline Taubaté & $14 /$ set & $21 /$ set & $11 /$ out & $13 /$ set & 03/out & $10 /$ out \\
\hline D. virginiana & 05/out & 19/out & $05 /$ nov & $10 /$ out & $25 /$ out & $01 /$ nov \\
\hline
\end{tabular}

TABELA 2- Tamanho médio e estimativa da viabilidade dos grãos de pólen de duas cultivares de $D$. kaki e da espécie D. virginiana Eldorado do Sul, no ciclo produtivo de 2011/2012.

\begin{tabular}{|c|c|c|c|c|c|c|c|c|}
\hline \multirow[b]{2}{*}{ Cultivar/ Espécie- } & \multicolumn{2}{|c|}{ Grão Normal } & \multicolumn{2}{|c|}{ Grande } & \multicolumn{2}{|c|}{ Pequeno } & \multirow{2}{*}{\multicolumn{2}{|c|}{ Viabilidade (\%) }} \\
\hline & $\begin{array}{l}\text { E.T* } \\
(\mu \mathrm{m})\end{array}$ & $\begin{array}{l}\text { E.L.* } \\
(\mu \mathrm{m})\end{array}$ & $\begin{array}{l}\text { E.T. } \\
(\mu \mathrm{m})\end{array}$ & $\begin{array}{l}\text { E.L. } \\
(\mu \mathrm{m})\end{array}$ & $\begin{array}{l}\text { E.T. } \\
(\mu \mathrm{m})\end{array}$ & $\begin{array}{l}\text { E.L. } \\
(\mu \mathrm{m})\end{array}$ & & \\
\hline Pomelo & 40,68 & 40,81 & 50,40 & 50,53 & 35,49 & 35,44 & 92,18 & $a^{* *}$ \\
\hline Mikado & 43,29 & 43,10 & 47,17 & 47,15 & 40,00 & 39,84 & 98,39 & $\mathrm{a}$ \\
\hline D. virginana & 44,67 & 44,77 & 48,99 & 49,04 & 40,22 & 40,68 & 97,24 & $\mathrm{a}$ \\
\hline
\end{tabular}

*E.T. Eixo Transversal; E.L. Eixo longitudinal.

**Médias seguidas pela mesma letra não diferem estatisticamente entre si, pelo teste de Tukey, ao nível de 5\% de probabilidade.

TABELA 3- Tamanho médio e estimativa da viabilidade dos grãos de pólen de duas cultivares de $D$. kaki e da espécie D. virginiana, Eldorado do Sul, no ciclo produtivo de 2012/2013.

\begin{tabular}{|c|c|c|c|c|c|c|c|c|}
\hline \multirow{2}{*}{ Cultivar/ Espécie } & \multicolumn{2}{|c|}{ Grão Normal } & \multicolumn{2}{|c|}{ Grande } & \multicolumn{2}{|c|}{ Pequeno } & \multirow{2}{*}{\multicolumn{2}{|c|}{ Viabilidade (\%) }} \\
\hline & $\begin{array}{l}\text { E.T* } \\
(\mu \mathrm{m})\end{array}$ & $\begin{array}{l}\text { E.L.* } \\
(\mu \mathrm{m})\end{array}$ & $\begin{array}{l}\text { E.T. } \\
(\mu \mathrm{m})\end{array}$ & $\begin{array}{l}\text { E.L. } \\
(\mu \mathrm{m})\end{array}$ & $\begin{array}{l}\text { E.T. } \\
(\mu \mathrm{m})\end{array}$ & $\begin{array}{l}\text { E.L. } \\
(\mu \mathrm{m})\end{array}$ & & \\
\hline Pomelo & 41,93 & 42,15 & 47,83 & 48,16 & 37,20 & 37,20 & 97,67 & $a^{* *}$ \\
\hline Mikado & 39,99 & 40,02 & 44,27 & 44,28 & 36,84 & 36,98 & 85,87 & $\mathrm{~b}$ \\
\hline D. virginiana & 46,46 & 46,38 & 51,94 & 51,90 & 42,11 & 42,15 & 95,51 & $\mathrm{a}$ \\
\hline
\end{tabular}

*E.T. Eixo Transversal; E.L. Eixo longitudinal.

**Médias seguidas pela mesma letra não diferem estatisticamente entre si, pelo teste de Tukey, ao nível de 5\% de probabilidade. 


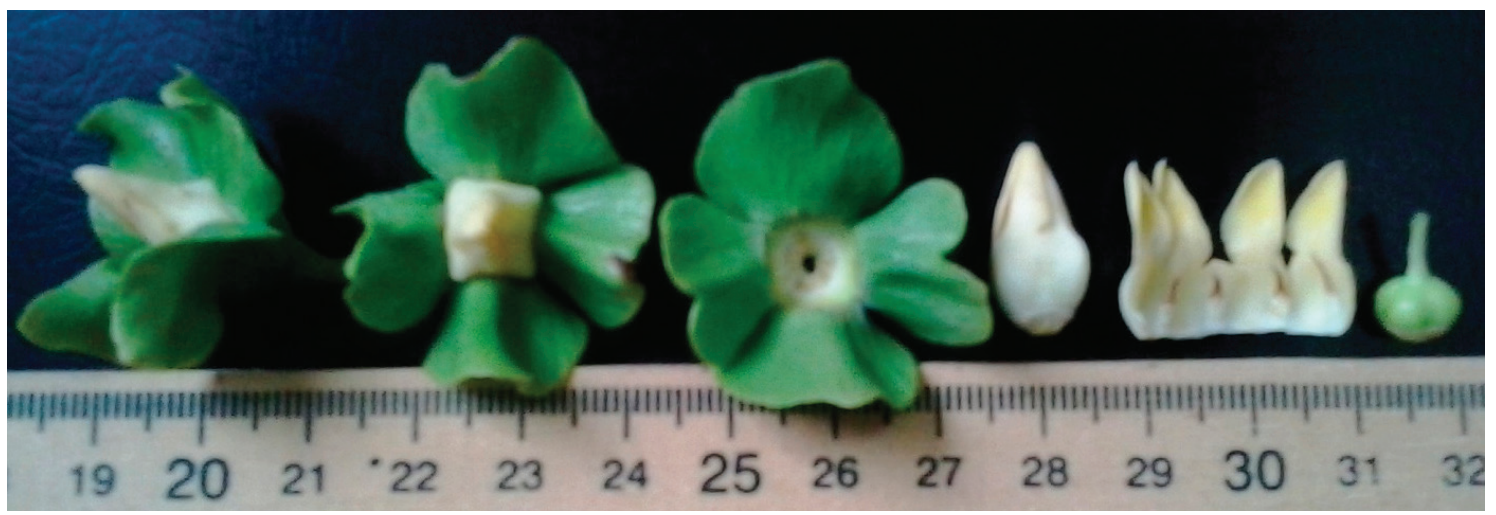

FIGURA 1- Flor feminina de Diospyros kaki. Da esquerda para direita: botão floral em estágio de balão, visão lateral e frontal. Sépalas com coloração verde, destacadas, que irão tornar-se o cálice do fruto. Botão floral com pétalas fechadas de coloração branca (estádio de balão). Pétalas destacadas mostrando estames não funcionais inseridos em sua base. Ovário tetrâmero com estigma.

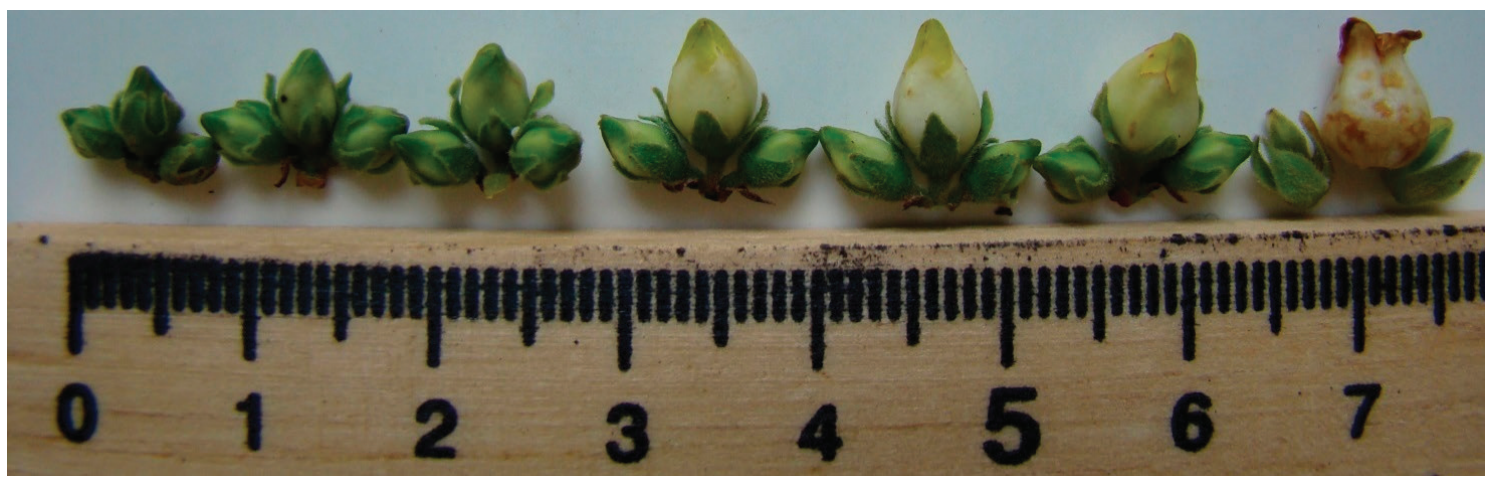

FIGURA 2- Diferentes estádios da flor masculina durante o período de florescimento em $D$. virginiana. Da esquerda para a direita: início da emergência das inflorescências; em estádio intermediário, ocorre a mudança na cor da pétala de verde para branca, último estádio da flor em antese, queda das flores (ausência de ovário).

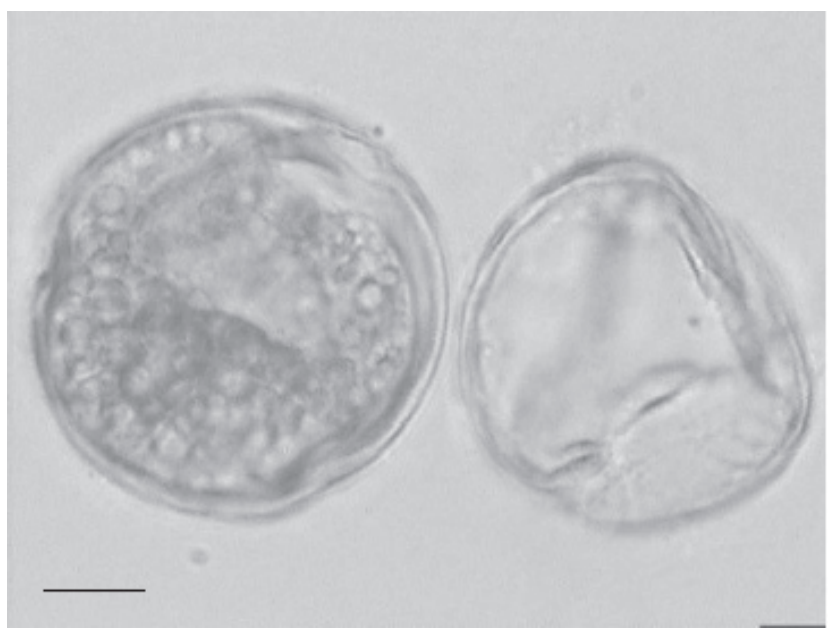

FIGURA 3- Grãos de pólen da cultivar Pomelo viável (esquerda) e inviável (direita). Escala $10 \mu \mathrm{m}$. 


\section{CONCLUSÕES}

O período de florescimento das cultivares estudadas concentrou-se no mês de setembro. Nos dois ciclos de produção avaliados, as cultivares Rama Forte e Pomelo foram as mais precoces para o período inicial do florescimento, em relação às demais cultivares, sendo a 'Costata' a mais tardia nos dois anos avaliados. Podem-se recomendar as duas primeiras para regiões mais quentes e antecipar ainda mais sua oferta no mercado, e a última para locais com possibilidade de geada tardia ou para ofertar frutos no mercado em período diferenciado das principais cultivares comercializadas.

Os grãos de pólen foram encontrados em duas das nove cultivares de D. kaki avaliadas (Pomelo e Mikado) e em D. virginiana, todas apresentando alta percentagem de viabilidade.

As flores da cultivar Mikado apresentaram produção de pólen viável, o que não havia sido relatado anteriormente.

As demais cultivares não apresentaram flores com estames funcionais.

\section{REFERÊNCIAS}

AGUSTÍ, M. Fruticultura. Espanha: Mundi-Prensa, 2010. 507 p.

BERGAMASCHI, H.; GUADAGNIN, M.R.; CARDoso, L.S.; SILVA, M.I.G. Clima da Estação Experimental da UFRGS (e região de abrangência).

CAVALCANTE, H.C.; SCHIFINO-WITTMANN, M.T.; DORNELLES, A.L.C. Meiotic behaviour and pollen fertility in na open-pollinated population os "Lee" mandarin [Citrus clementina $\mathrm{x}$ (C. paradise $\mathrm{x}$ C. tangerina)]. Scientia Horticulturae, Amsterdam, v.86, n2, p.103-114, 2000.

COMISSÃO DE QUÍMICA E FERTILIDADE DO SOLO - RS/SC. Manual de Adubação e Calagem para os Estados do Rio Grande do Sul e Santa Catarina. Porto Alegre: SBCS - Núcleo Regional Sul, 2004. 394 p.

FAO. Faostat agriculture data, agricultural productions, crops primary. Disponível em: $<$ http:// faostat.fao.org/ > . Acesso em: 14 abr. 2014.
GARCIA-CARBONEL, S. et al. Phenological growth stages of the persimmon tree (Diospyros kaki). Annals of Applied Biology, Great Britain, v. 141, p. 73-76, 2002.

GRELlMANN, E. O.; SIMONETTO, P. R.; FIORAVANÇO, J. C. Comportamento fenológico e produtivo de cinco cultivares e uma seleção de caquizeiro em Veranópolis, Rio Grande do Sul, Brasil. Pesquisa Agropecuária Gaúcha, Porto Alegre, v. 9, n. 1-2, p.71-76, 2003.

GRYGORIEVA, O. et al. Pollen characteristics in some persimmon species (Diospyros spp.). Agriculture, Geneva, v. 56, n. 4, p.121-130, 2010.

IBGE - Instituto Brasileiro Geografia e Estatística. Anuário estatístico brasileiro. Disponível em: $\leq \mathrm{ftp}$ ://ftp.ibge.gov.br/Producao_Agricola/ > Acesso em: 14 abr. 2014.

MARTINS, F. P.; PEREIRA, F. M. Cultura do caquizeiro. Jaboticabal: Funep, 1989. 71 p.

MORELlATO, L. P. C. Fenologia: ferramenta para conservação, melhoramento e manejo de recursos vegetais arbóreos. Colombo: Embrapa Florestas, 2007. OJIMA, M.; DALL'ORTO, F.A.C.; BARBOSA, W.; TOMBOLATO, A.F.C.; RIGITANOM, O.Frutificação alternada em caqui cultivar pomelo (IAC 6-22). Bragantia, Campinas, v. 44, n. 1, p. 481-486, 1985.

RAMSEY, J.; SCHEMSKE, D. W. Pathways, mechanisms and rates of polyploid formation in flowering plants. Annual Review of Ecology Sistematics, Palo Alto, v. 29, p. 467-501, 1998.

YASUI, K. Studies of Diospyros kaki. I Contributions from the Hull Botanical Laboratory 209. Botanical Gazette, Chicago, v. 60, n. 5, p. 362-373, 1915.

STRECK, E. V. et al. Solos do Rio Grande do Sul. 2. ed. Porto Alegre: Emater/RS, 2008. 222 p. 